\title{
Oxidative stress and its downstream signaling in aging eyes
}

This article was published in the following Dove Press journal:

Clinical Interventions in Aging

II April 2014

Number of times this article has been viewed

\author{
María Dolores Pinazo- \\ Durán ${ }^{1, *}$ \\ Roberto Gallego-Pinazo,** \\ Jose Javier García-Medina, ${ }^{1,3, *}$ \\ Vicente Zanón-Moreno',4 \\ Carlo $\mathrm{Nucci}^{5}$ \\ Rosa Dolz-Marco ${ }^{2}$ \\ Sebastián Martínez-Castillo² \\ Carmen Galbis-Estrada' \\ Carla Marco-Ramírez' \\ Maria Isabel López-Gálvez, \\ David J Galarreta ${ }^{6, *}$ \\ Manuel Díaz-Llópis ${ }^{4, *}$ \\ 'Ophthalmic Research Unit "Santiago \\ Grisolía”, Valencia, Spain; ${ }^{2}$ Department \\ of Ophthalmology, Macula Section, The \\ University and Polytechnic Hospital \\ La Fe, Valencia, Spain; ${ }^{3}$ Department of \\ Ophthalmology, University Hospital \\ Reina Sofia, Murcia, Spain; ${ }^{4}$ Faculty \\ of Medicine, University of Valencia, \\ Spain; ${ }^{5}$ University of Rome Tor \\ Vergata, Rome, Italy; ${ }^{6}$ Instituto de \\ Oftalmobiología Aplicada (IOBA), \\ Valladolid, Spain \\ * Members of the Spanish Net of \\ Ocular Pathology of the Instituto de \\ Salud Carlos III (Madrid), OFTARED
}

Correspondence: María Dolores PinazoDurán

Santiago Grisolía Ophthalmic Research Unit (FISABIO), University Hospital

Doctor Peset, Avenida Gaspar

Aguilar 90, Valencia 46017, Spain

Tel +3496I 622497

Email dolores.pinazo@uv.es
Background: Oxidative stress (OS) and its biomarkers are the biochemical end point of the imbalance between reactive oxygen species (ROS) production and the ability of the antioxidant (AOX) biological systems to fight against oxidative injury.

Objective: We reviewed the role of OS and its downstream signaling in aging eyes.

Methods: A search of the literature and current knowledge on the physiological and pathological mechanisms of OS were revisited in relation to the eyes and the aging process. Most prevalent ocular diseases have been analyzed herein in relation to OS and nutraceutic supplements, such as dry-eye disorders, glaucoma, age-related macular degeneration, and diabetic retinopathy.

Results: Clinical, biochemical, and molecular data from anterior and posterior eye segment diseases point to OS as the common pathogenic mechanism in the majority of these ocular disorders, many of which are pathologies causing visual impairment, blindness, and subsequent loss of life quality. Studies with nutraceutic supplements in aging eye-related pathologies have also been reviewed.

Conclusion: OS, nutritional status, and nutraceutic supplements have to be considered within the standards of care of older ophthalmologic patients. OS biomarkers and surrogate end points may help in managing the aging population with ocular diseases.

Keywords: oxidative stress, eyes, aging, ophthalmic diseases, antioxidants, epidemiology

\section{Introduction}

Oxygen $\left(\mathrm{O}_{2}\right)$ is essential for life, as it plays a major role in the energy cycle of living organisms and is fundamental for the aerobic breathing of cells and tissues. From a chemical point of view, any reaction ending with a gain of electrons results in a reduction process, and in contrast, when concluding with losing electrons results in an oxidation reaction. ${ }^{1}$

These concepts of reduction-oxidation (redox) are based on electron-transfer events. Compounds capable of accepting electrons are oxidizing agents, and those able to assign electrons are reducing agents (Figure 1). Under normal conditions (during aerobic metabolism), the $\mathrm{O}_{2}$ undergoes tetravalent reduction to water $\left(\mathrm{H}_{2} \mathrm{O}\right)$. However, in situations that induce an incomplete reduction, very unstable and reactive species are formed, the so-called reactive oxygen species (ROS). In general, ROS are classified into two groups: radical species and nonradical species. ${ }^{2}$

A free radical (FR) is an atom or molecule that contains an unpaired electron in its outer orbital. This situation confers them instability and the need to lose/gain an electron in order to get stable. Among the nonradical oxygen species are hydrogen peroxide $\left(\mathrm{H}_{2} \mathrm{O}_{2}\right)$, ozone $\left(\mathrm{O}_{3}\right)$, and nitric oxide $(\mathrm{NO})$. There is a typical sequential order 


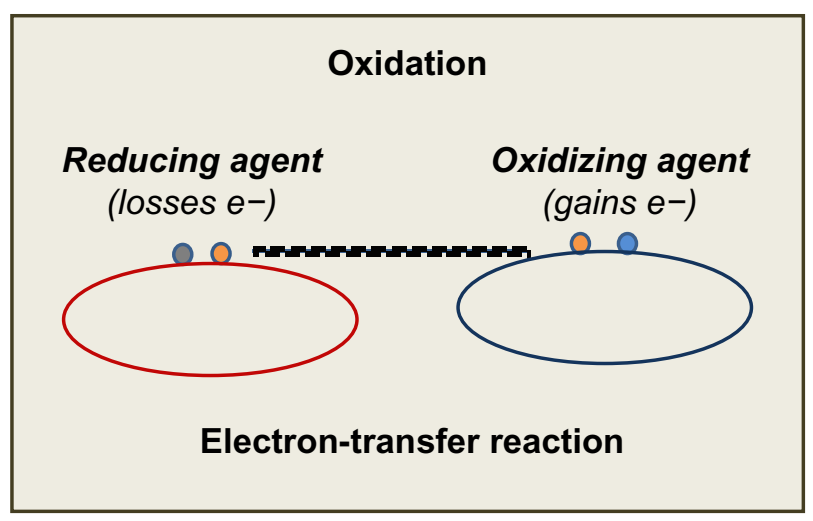

Figure I Redox reactions and Electron-transfer. Reducing and oxidizing agents.

in ROS generation, characterized by the production in the first place of the superoxide anion $\left(\mathrm{O}_{2}{ }^{\circ}\right)$, followed by $\mathrm{H}_{2} \mathrm{O}_{2}$ and the hydroxyl radical $\left(\mathrm{OH}^{\cdot}\right) .^{3-6}$

$\mathrm{O}_{2} \cdot$ is formed in multiple processes, and is the most abundant among the ROS. It possesses a half-life of milliseconds. Although $\mathrm{O}_{2}{ }^{\cdot}$ is not reactive enough to attack macromolecules directly, it can start an ROS chain formation. $\mathrm{H}_{2} \mathrm{O}_{2}$, a non-radical oxygen species, has the ability to generate other ROS. It is a small molecule lacking electrochemical charge, diffuses easily, and can pass through cell membranes, propagating its effects farther than other species. $\mathrm{OH}^{*}$ is the most powerful and harmful of all oxygen species. However, its short half-life (10 seconds) is a limiting condition to the diffusion capacity. It is formed from $\mathrm{O}_{2}$ and $\mathrm{H}_{2} \mathrm{O}_{2}$ in the presence of transition metals ( $\mathrm{Fe} /$ iron) during the sequential reactions of Haber-Weiss and Fenton:

$$
\begin{gathered}
\mathrm{O}_{2}^{--}+\mathrm{H}_{2} \mathrm{O}_{2} \rightarrow \mathrm{O}_{2}+\mathrm{OH}^{\cdot}+\mathrm{OH}^{-} \\
\mathrm{Fe}^{2+}+\mathrm{H}_{2} \mathrm{O}_{2} \rightarrow \mathrm{Fe}^{3+}+\mathrm{OH}^{\cdot}+\mathrm{OH}^{-}
\end{gathered}
$$

\section{Oxidative stress}

All biomolecules can be attacked by ROS: lipids, proteins, and nucleic acids. Among them, lipids are probably the most susceptible to undergo oxidation. ${ }^{7}$ All cell membranes are rich in polyunsaturated fatty acids (PUFAs), which are easily injured by oxidizing agents. There are endogenous and exogenous defense mechanisms against oxidative attack. Oxidative stress (OS) and its biomarkers are the biochemical end point of the imbalance between ROS production and the ability of antioxidant (AOX) biological systems to counteract the effects of ROS metabolites. ${ }^{6,7}$

Cells maintain a reducing environment by the corresponding enzymes and the constant supply of metabolic energy. The OS effects depend on the intensity of such abnormalities and the cellular response. If the cell is unable to overcome and to recover its function, the exogenous and endogenous AOX defenses cannot counter it, and the cell can become extinct (Figure 2). However, ROS have also been shown to function as signaling molecules. ${ }^{8}$ This underlies relevant mechanisms that are essential for the integrity of living organisms and their aging process. Knowledge of the pathways that regulate ROS homeostasis is pivotal for relieving the deleterious effects of ROS in cells and tissues. Further research in this topic can provide strong evidence about specificity in ROS signaling in health and disease. ${ }^{8}$

Among the best known AOXs are the enzymes superoxide dismutase (SOD), catalase (CAT), and glutathione peroxidase (GSH-Px). ${ }^{9}$ Since the discovery of SOD in $1969,{ }^{10}$ it has been assumed that ROS participate in the pathogenic mechanisms of various diseases and abnormal conditions. In 1956, Harman proposed the theory of FRs and aging, ${ }^{11}$ which was supported by the basic theory of the relationship between the duration of life, metabolic rate, and $\mathrm{O}_{2}$ consumption by organisms. Gerschman and Fenn ${ }^{12}$ and Gerschman et $\mathrm{al}^{13,14}$ demonstrated that FRs are toxic to our body.

OS has been associated with such pathologies as atherosclerosis, Parkinson's and Alzheimer's diseases, aging processes, dermatitis, cancer, asthma, neurodegeneration, infertility, atherosclerosis, hypertension, diabetes, and rheumatoid arthritis, among others. ${ }^{7,9,15-20}$ OS has also been implicated in ophthalmic processes, including ocular surface disorders, cataracts, glaucoma, diabetic retinopathy (DR), retinitis pigmentosa, toxic neuropathies, uveitis, and age-related macular degeneration (AMD)..$^{13,21-28}$ However, the exact signaling pathways regulated by ROS, especially

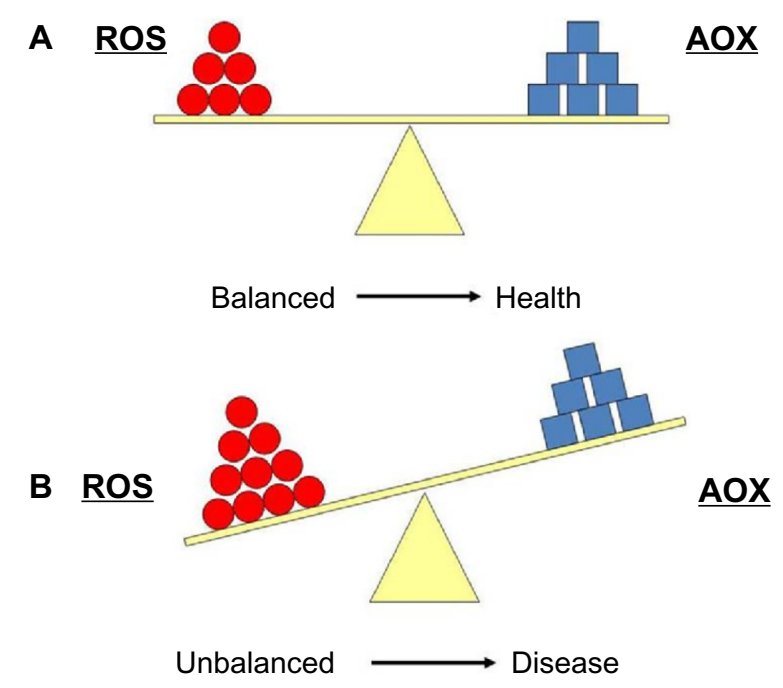

Figure 2 (A) Equilibrium between reactive oxygen species (ROS) production and antioxidant defense (AOX). (B) Imbalanced situation between ROS and AOX, which is associated with many pathologies. 
in age-related eye diseases, need further investigation. Delineating the specific signals modulated by ROS is of great diagnostic and therapeutic interest.

Biomarkers and surrogate end points of OS and its downstream effectors have been extensively studied in relation to ocular diseases. Ocular oxidative damage can be determined by direct/indirect methods in biological samples, including such techniques as enzymatic colorimetric assay or highperformance liquid chromatography. With these assays, oxidative activity can be measured: 1) malondialdehyde (MDA), 4-hydroxynonenal, oxidation of nucleic acids 8-hydroxy-2' deoxyguanosine or 8-oxo-7,8-dihydro- $2^{\prime}$-deoxyguanosine; 2 ) the isoprostanes and the prostaglandin-like compounds that are produced in vivo independently of cyclooxygenase enzymes; and 3) AOX capacity (total AOX capacity [TAC]) can also be determined, as well as enzymatic activities (SOD, CAT, GSH-Px, vitamins) and FR scavengers (GSH). All these oxidative and AOX activities can be assayed on various ophthalmological samples, including aqueous humor, vitreous body, and tear biopsies, and in the blood, urine, or saliva. ${ }^{23-26}$ Comparing the results of determinations of oxidative and AOX status may reflect the balance between them and the degree of OS by laboratory tests performed in samples from our ophthalmic patients.

\section{Antioxidant mechanisms}

The human body has some natural AOX defense systems to diminish the harmful action of continuous ROS production. ${ }^{7,9,10,21}$ These defenses are located in the cytoplasm, cellular membrane, and extracellular space, and can be classified as follows.

\section{Enzymatic defense systems}

These consist of intracellular mechanisms in which SOD, CAT, and GSH-Px eliminate ROS once formed. SODs are metalloproteins that accelerate the dismutation of superoxide to hydrogen peroxide. Protective action is associated with CATs and peroxidases in order to avoid the accumulation of hydrogen peroxide that would otherwise be converted into $\mathrm{OH}^{*}$. There are two main molecular types of SOD in humans: the cytosolic one (CuZnSOD), which contains copper and zinc, and the mitochondrial one (MnSOD), which contains manganese. CAT is located in the peroxisome and mitochondria, and its function consist of catalyzing the dismutation of hydrogen peroxide to water and molecular oxygen. It has been demonstrated that high concentrations of hydrogen peroxide stimulate CAT activity, while low concentrations are preferentially catalyzed by peroxidases. GSH-Px is located in cytosol and mitochondria. It is known that this works by eliminating hydroperoxides, transforming them into water. This reaction is associated with the transformation of reduced glutathion (GSH) into oxidized GSH (GSSG). ${ }^{29,30}$

\section{Free radical scavengers}

FR scavengers slow down the reactions of oxidation or "catch" FRs, transforming them into less aggressive compounds. They can be hydrosoluble and cytosolic (GSH and $\mathrm{C}$ vitamin) or liposoluble, located in the membrane (vitamin $\mathrm{E}$ and carotenoids). Vitamin $\mathrm{C}$ is the main hydrosoluble AOX, and may also regenerate tocopherol (vitamin E), which is one of the main liposoluble AOXs in cellular membranes, together with carotenoids ( $\beta$-carotene, lutein, zeaxanthin, and lycopenes). ${ }^{31} \mathrm{GSH}$ is considered the most abundant AOX in cytosol, nucleus, and mitochondria, making the ratio of GSH:GSSG a good way to measure OS.

\section{Chelating agents of transition metals}

These are molecules that bind iron and copper, like the flavonoids. In this way, they avoid these metals to act in Fenton and Haber-Weiss reactions. ${ }^{3,4}$ Some authors prefer another classification according to the AOX source. In this manner, AOXs can be endogenous (synthesized by the own body), such as GSH, SOD, and CAT. But they also can be exogenous (only obtained from food), such as vitamins $\mathrm{C}$ and $\mathrm{E}$, carotenoids, flavonoids and oligoelements. Besides these AOX defense systems, there are also repairing and exchanging mechanisms of damaged biomolecules. .,29,31 $^{9}$

\section{Aging eyes as targets of oxidative stress}

The predicted gain in life span in most countries is expected to lead progressively to an increase in the number of older people suffering age-related chronic diseases in the next decade. Moreover, within the cycle of life, aging can be defined as a progressive loss of the efficacy of physiological and biochemical processes occurring until death. Several theories have postulated the link between OS and aging, of which the most famous is the FR theory of aging, ${ }^{11}$ which maintains that production of FRs and the subsequent FR damage increases with age.

The eye is an organ that is continuously exposed to ionizing radiation, pollutants, industrial smoke, and driving fumes, which makes the eyeballs extremely susceptible to oxidative attack. The retina is a photosensitive tissue that is affected by light rays and undergoes high metabolic activity. Furthermore, the retina contains a higher concentration of 
PUFAs than other body tissues. ${ }^{32}$ Because of this, our retinas are vulnerable to the action of ROS. Also, those endogenous oxygen species generated into the eyes can induce ROSrelated ocular disorders, as mentioned earlier. OS processes have been associated with a wide variety of eye diseases, such as ocular surface diseases, ${ }^{21}$ cataracts, ${ }^{22}$ glaucoma, ${ }^{23}$ uveitis,${ }^{33}$ retinopathies, and AMD. ${ }^{25,26,28,33,34}$ All of these pathologies are related to age, which is in agreement with the Harman theory of FRs in aging. ${ }^{11}$

In this context, it is conceivable that the concentration of endogenous AOX sources suffers a significant decrease with age, and likewise, ROS production increases with aging. Moreover, OS processes associated with ocular pathologies contribute to their progression. Many of these diseases are prevalent pathologies leading to blindness. We review these visual impairment-inducing disorders in relation to OS, nutrition, and nutraceutic formulations.

\section{Oxidative stress-related ocular pathologies Ocular surface diseases}

Dry-eye disorder (DED) is a recently introduced term that defines the ocular surface dysfunction leading to tear-film impairment and dry eyes. DEDs are complex diseases involving the lacrimal glands, eyelids, and tear film, as well as a variety of ocular surface tissues, including epithelial, inflammatory, immune, and goblet cells..$^{35-38}$

DED displays high prevalence rates worldwide, ${ }^{35,39}$ and usually affects people aged 65 years and above. Moreover, DED is more common in women, as emphasized by the Women's Eye Health Organization and other large studies, ${ }^{40-42}$ with an estimation of about 3.23 million American women suffering from DED.

OS plays a significant role in a wide spectrum of ocular conditions, including ocular surface pathologies. ${ }^{43,44}$ As a result of the imbalance between prooxidant and AOX sources, the ocular surface structures can be damaged. It has also been reported that tears provide key molecules for preventing OS injury to the cornea. ${ }^{45}$ Evidence is growing that constant exposure to OS is involved in the initiation and progression of cellular injury that leads to ocular surface pathology in DED, conjunctivochalasis, ultraviolet light-induced ocular surface epithelial injury, and tobacco smoke-induced ocular surface epithelial damage. OS and its downstream signaling are linked to a series of cellular events. This strongly indicates that OS activates cell regulatory molecules that may alter the regenerative capacity of the corneal epithelial cell layer under dry-eye conditions, as reported by Nakamura et al in a blink-suppressed dry-eye rat model. ${ }^{46}$ The authors speculated that an imbalance in the tear-film status, a synergistic effect between prolonged exposure to atmospheric oxygen, and insufficient supplementation of AOX, agents may have induced the overexpression of ROS production on the ocular surface. In this context, AOX supplements may help in counteracting the oxidative status in the altered ocular surface.

A significant increase in oxidative activity and a decrease in AOX defenses in ocular fluids and tissues, as well as in plasma samples, have been associated with DED patients. ${ }^{43-45}$ In fact DED has been recognized as an OS-induced process. In addition, it has recently been reported that chronic inflammation plays a crucial role in DED, as measured by the release of cytokines and chemokines that initiate or amplify the body's immune and inflammatory response. ${ }^{46-48}$ Significantly increased levels of cytokines/chemokines have been detected in the tear fluid and conjunctiva of people with DED compared to normal eyes. ${ }^{46-50}$ Certain cytokines, such as interleukin 6, may induce cells to produce other compounds that play a role in the development of inflammation, such as prostaglandins, enzymes, and ROS.$^{51}$ Tsubota et al ${ }^{52}$ recently suggested a new approach to the aging process and DED through controlling levels of calories and/or ROS in order to prevent DED.

OS can harm the ocular surface by inducing serious tissue damage to the cornea and conjunctiva, leading to visual impairment that may be counteracted, at least in part, by appropriate diet and nutritional supplements.

\section{Glaucoma}

Glaucoma is the second-most relevant cause of blindness worldwide. The disease is a progressive optic neuropathy, often caused by elevated intraocular pressure (IOP) consequent to abnormal high resistance to aqueous humor drainage via the trabecular meshwork and Schlemm's canal. ${ }^{53}$ Regulation of IOP depends on the balance of complex mechanisms involved in the production and outflow of aqueous humor, including the stability and survival of cellular phenotypes involved in this process and the correct maintenance of homeostasis. ${ }^{54,55}$ The most frequent glaucoma type is the chronic clinical manifestation known as the primary open-angle glaucoma (POAG), mainly affecting individuals aged 40 years or more. ${ }^{53}$ In spite of elevated IOP, apoptosis has been recognized as the end point for retinal ganglion cell (RGC) death in any glaucoma type. ${ }^{54-56}$ 
Oxidative damage was found in the deoxyribonucleic acid (DNA) of POAG patients. ${ }^{57}$ Moreover, a significant correlation between oxidative DNA damage and IOP was described in glaucomatous patients. It has also been shown that POAG patients display a genetic background rendering them susceptible to ROS-induced damage because of a more frequent deletion, compared to control individuals, of the gene encoding for GSH $S$-transferase, pivotal for the AOX defense mechanism. ${ }^{57}$ It has to be considered that OS occurs in the trabecular meshwork and Schlemm's canal, as well as in the posterior eye-segment structures (RGCs and optic nerve fibers). OS has also been linked to POAG by increasing flow resistance in the anterior chamber of the eye in the presence of high levels of hydrogen peroxide. Abundant AOX activity of the trabecular meshwork and aqueous humor of these patients has also been reported in POAG individuals. ${ }^{23}$ Recent reports implicate OS, inflammation, ischemia, and excitotoxicity among the proapoptotic factors for RGCs in glaucomatous patients. ${ }^{58}$ Corresponding markers to these etiopathogenic mechanisms have been subsequently described. ${ }^{59}$ The most probable OS biomarkers for POAG are shown in Table 1.

However, RGC loss in glaucoma is still a mystery to scientists. In response to glaucomatous stimuli, cross talk between proapoptotic signals (caspase activation and mitochondrial dysfunction) and survival promoters (neurotrophins) determines the fate of RGCs. ${ }^{54-56}$ From a molecular viewpoint, it is difficult to address the role of OS in glaucoma standards of care. Future studies in OS and its downstream signaling may be useful for better managing this insidious disease

\section{Retinal diseases}

The retina is extremely vulnerable to ROS damage..$^{21,32}$ Major reasons for this susceptibility are constant exposure

Table I Oxidative stress biomarkers in primary open-angle glaucoma

\begin{tabular}{|c|c|c|c|}
\hline Reference & Biomarker & Sample & $\begin{array}{l}\text { Levels in } \\
\text { POAG }\end{array}$ \\
\hline Ames et al ${ }^{19}$ & AOXT & Dietary antioxidants & $\downarrow$ \\
\hline \multirow[t]{2}{*}{ Zanón-Moreno et a ${ }^{23}$} & MDA & Aqueous humor & $\uparrow$ \\
\hline & AOXT & Aqueous humor & $\downarrow$ \\
\hline \multirow[t]{2}{*}{ Galbis-Estrada et $\mathrm{al}^{51}$} & IL-6 & Human tears & $\uparrow$ \\
\hline & TNF-a & Human tears & $\uparrow$ \\
\hline \multirow[t]{2}{*}{ Huang et $\mathrm{a}^{55}$} & CASPASES 8,9 & Rat retinal lysates and retinal whole mounts & $\uparrow$ \\
\hline & PARP I & $\begin{array}{l}\text { Rat retinal lysates and retinal whole mounts } \\
\text { and cross-sections }\end{array}$ & $\uparrow$ \\
\hline \multirow[t]{4}{*}{ Pinazo-Durán et al ${ }^{56}$} & MDA & Aqueous humor & $\uparrow$ \\
\hline & AOXT & Aqueous humor & $\downarrow$ \\
\hline & CASPASE 3 & Aqueous humor & $\uparrow$ \\
\hline & PARP I & Aqueous humor & $\uparrow$ \\
\hline \multirow[t]{2}{*}{ Saccá and Izzotti ${ }^{57}$} & NO & Human trabecular meshwork & $\uparrow$ \\
\hline & Endothelin I & Aqueous humor & $\downarrow$ \\
\hline \multirow[t]{3}{*}{ Tezel et al ${ }^{58}$} & GAPDH & Retinal lysates & $\uparrow$ \\
\hline & HSP72 & Retinal lysates & $\uparrow$ \\
\hline & Glutamine synthetase & Retinal lysates & $\uparrow$ \\
\hline \multirow[t]{3}{*}{ Pinazo-Durán et a $\left.\right|^{59}$} & MDA & Aqueous humor & $\uparrow$ \\
\hline & AOXT & Aqueous humor & $\downarrow$ \\
\hline & SOD & Aqueous humor & $\uparrow$ \\
\hline Bazán et $a^{60}$ & NPD I & ARPE 19 cells & $\downarrow$ \\
\hline \multirow[t]{3}{*}{ Galbis-Estrada et al $\left.\right|^{77}$} & MDA & Rat retinal cross-sections, and lysates & $\uparrow$ \\
\hline & AOXT & Rat retinal cross-sections and lysates & $\downarrow$ \\
\hline & GSH & Rat retinal cross-sections and lysates & $\downarrow$ \\
\hline \multirow[t]{3}{*}{ Zanón-Moreno et al ${ }^{102}$} & Vitamin $\mathrm{E}$ & Serum & $\downarrow$ \\
\hline & Vitamin C & Serum & $\downarrow$ \\
\hline & GSH Px & Serum & $\downarrow$ \\
\hline
\end{tabular}

Abbreviations: AOXT, total antioxidant activity; MDA, malondyaldehyde; IL-6, Interleukin-6; TNF-a, tumor necrosis factor-alpha; PARP-I, poly adenyl rybose polymerase-I; CS 3, caspase 3; NO, nitric oxide; GAPDH, glyceraldehyde-3-phosphate dehydrogenase; HSP72, heat shock protein 72; GSH, glutathione; SOD, superoxide dismutase; NPD I, 10,17S-docosatriene; GSH Px, glutathione peroxidase. 
to visible light, causing photooxidation, and high oxygen consumption, due to the great energy demanded. ${ }^{32}$ In addition, the extraordinary concentration of PUFAs makes the retina prone to lipid oxidation. ${ }^{60}$

Also, the retinal pigment epithelium (RPE) is subjected to OS. The ROS formed from phagocytosis and lipid peroxidation and/or focal light, together with high oxygen tension in the macula, point to the fact that OS is extremely important in the RPE. Moreover, the RPE phagocytic function provides an additional oxidative burden because of the constant shedding of the outer segments of photoreceptors. ${ }^{61,62}$

The major PUFA in the retina is the docosahexaenoic acid (DHA), highly concentrated in the outer segment of the photoreceptors. Retinal DHA is a target for ROS, but at the same time it plays a key role in the homeostasis and function of the photoreceptors and RPE under physiologic conditions. ${ }^{63-65}$ When OS increases, DHA activates prosurvival signaling via neuroprotectin D1, which is its major mediator. ${ }^{63-65}$ The presence of lipofuscin, a product of the degradation of photoreceptors, may also act as a photosensitizer, ${ }^{66}$ leading to an increase of the risk of oxidative injury. However, studies in this field are steadily growing. Curcio et a ${ }^{67}$ emphasized that the RPE secretes apolipoprotein B particles into Bruch's membrane, and these accumulate with age, which in turn may form a lipid wall, a precursor of the basal linear deposit. Then, certain constituents of the described aggregates may interact with ROS, resulting in proinflammatory peroxidised lipids leading to upregulation of cytokines/chemokines, as well as provoking neovascularization.

However, in the RPE, OS is also capable of inducing protective pathways, such as the phosphatidylinositide 3-kinase/Akt and nuclear factor erythroid-2-related factor 2 pathways. Vascular endothelial growth factor and neuroprotectin D1 signaling acts also by protecting cells and tissues, as reported by Faghir and Bazan ${ }^{68}$ and Klettner ${ }^{69}$ in recent publications.

Many retinal disorders have been related to oxidative damage. The pathophysiology of some of them includes oxidative damage to the RPE, as in AMD or Stargardt disease. ${ }^{64,65}$ The mechanism of RPE injury has not been clearly described, but it may be related to A2E (a lipofuscin fluorophore). ${ }^{69,70-74}$ AMD, a leading cause of severe visual loss, is a multifactorial disease, and thus its pathogenesis remains poorly understood. Nevertheless, the important role of OS in the development of AMD has been demonstrated. In normal conditions, the RPE constantly phagocytizes the photoreceptor outer-segment membranes, but in AMD an RPE dysfunction leads to the accumulation of undigested material, called lipofuscin. ${ }^{69-73}$ Lipofuscin is deposited into insoluble aggregates in the RPE cells, displaying potent photoinducible properties, contributing to an enhancement and propagation of OS.

Other retinal dystrophies, such as retinitis pigmentosa, have been related to oxidative damage and progressive cell loss. ${ }^{74}$ Furthermore, the role of OS in mitochondrial neuroretinal diseases, such as Leber hereditary optic neuropathy, has also been documented. ${ }^{75}$

Increased intraocular iron results in oxidative damage to the retina. The retinal localization of lipid peroxidation (LPO) sites induced by iron or nicotine adenine dinucleotide phosphate (NADPH) have been described by histochemical and immunocytochemical assays. ${ }^{76,77}$ Also, increased superoxide anions were found in photoreceptor inner segments of adult $\mathrm{C} 57 \mathrm{Bl} / 6$ mice given intravitreous injections of $\mathrm{FeSO}_{4}$, and higher concentrations of the injected $\mathrm{FeSO}_{4}$ induced photoreceptor damage. ${ }^{78}$ Iron overload was identified "postmortem" in the RPE as well as in the photoreceptors of a 72-year-old patient with advanced macular geographic atrophy. ${ }^{79}$ Whether iron contributes to AMD pathogenesis or it is an AMD by-product remains unclear. Anyway, it can be speculated that AOX and iron chelators may be effective in preventing the development and progression of AMD. ${ }^{80}$ In fact, it has been recently demonstrated that iron chelators protect experimental animals from OS. ${ }^{81}$

The role of OS in diabetics and their eyes warrants particular attention. DR is the leading cause of blindness in developed countries. The presence of inappropriate glucose levels in the blood for years produces changes in retinal vessels that cause damage to the cells and progressively to the vision. These complications caused by the hyperglycemia are increased by excess generation of ROS and nitrogen species. ${ }^{82}$ This occurs mainly when diabetes is not properly controlled. FRs may function as signaling molecular and intra/extracellular defense mechanisms, as well as phagocytosis regulators. They may also act as molecules involved in biogenic vascular regulation. ${ }^{8}$ FR overproduction and/or insufficient removal results in vascular dysfunction, causing damage to cellular protein fragmentation, cross-linking and aggregation of amino acids, change in membrane lipids, and nucleic acid alteration by fragmentation, deletions, and mutations in the DNA chain. All these changes may trigger a nonphysiological cell death (necrosis), and constitute important OS biomarkers that can be measured in an appropriate and accurate form in diabetic patients, especially in the presence of chronic complications. ${ }^{83}$ Many types of ROS have been implicated in diabetes (both of mitochondrial and nonmitochondrial 
origin), among them NADPH oxidase, xanthine oxidase, uncoupled endothelial nitric oxide synthase, lipoxygenase, cyclooxygenase, cytochrome P450 enzymes, and other hemoproteins. ${ }^{84}$ Mitochondria are thought to be the main source of ROS generation in diabetics. Lipid peroxidation is one major pathogenic mechanism through which OS may damage the retina. ${ }^{25,32,84,85}$ Endothelial cells of retinal vessels and the RPE are constituents of the blood-retinal barrier. These vessels are stabilized by the presence of pericytes. During DR development, these pericytes disappear progressively, and the microvasculature undergoes progressive changes, such as altered endothelial cells, presence of capillary occlusions by endothelial cell proliferation, and neovascularization. ${ }^{86}$ The hyperglycemia also causes biochemical alterations through OS, leading to an increase in apoptosis of the retinal endothelial cells. ${ }^{87}$

Independently of manifestations of the ocular complications of diabetes, the main objectives for managing diabetics include the following challenges: 1) maximum nutritional and metabolic control (Tables 2 and 3), 2) normal blood glycemia levels to reduce the risk of complications, 3) adequate lipid and lipoprotein profiles to reduce the risk of cardiovascular disease, and 4) normal blood pressure levels to reduce cardiac and brain stroke risk.

Nutritional intervention in diabetes mellitus is essential for early identification and treatment of chronic diabetes complications by modifying the diet and to introduce adequate changes in lifestyle to prevent obesity, hypertension, dyslipidemia, neuropathy, cardiovascular disease, nephropathy, and retinopathy (see Table 2). It is widely recommended to gather data from individual nutrition facts by considering anthropometry, social and cultural demands, working conditions, and lifestyle of the diabetic patient (see Table 3).

Currently, OS is considered an important factor in the pathogenesis of DR. ${ }^{81-88}$ OS is measured indirectly by determining the oxidation of by-products of proteins and
Table 2 Biochemical parameters for optimal control in diabetic patients

\begin{tabular}{lll}
\hline Parameter & DM managing & Healthy population \\
\hline $\begin{array}{l}\text { Prepandrial } \\
\text { plasmatic glycemia }\end{array}$ & $90-130 \mathrm{mg} / \mathrm{dL}$ & $70-90 \mathrm{mg} / \mathrm{dL}$ \\
$\begin{array}{l}\text { Postpandrial } \\
\text { plasmatic glycemia }\end{array}$ & $<180 \mathrm{mg} / \mathrm{dL}$ & $70-135 \mathrm{mg} / \mathrm{dL}$ \\
$\mathrm{HbA}_{\mathrm{Ic}}(\%)$ & $<7 \%$ & $6 \%$ \\
Arterial pressure & $<130 / 80 \mathrm{mmHg}$ & $<140 / 90 \mathrm{mmHg}$ \\
Cholesterol & $<175 \mathrm{~m} / \mathrm{dL}$ & $<200 \mathrm{mg} / \mathrm{dL}$ \\
$\mathrm{LDL}$ & $<100 \mathrm{mg} / \mathrm{dL}$ & $<130 \mathrm{mg} / \mathrm{dL}$ \\
$\mathrm{HDL}$ & Man: $>40 \mathrm{mg} / \mathrm{dL}$ & Man: $>40 \mathrm{mg} / \mathrm{dL}$ \\
& Women: $50 \mathrm{mg} / \mathrm{dL}$ & Women: $>50 \mathrm{mg} / \mathrm{dL}$ \\
Triglycerides & $<150 \mathrm{mg} / \mathrm{dL}$ & $<150 \mathrm{mg} / \mathrm{dL}$ \\
\hline
\end{tabular}

Abbreviations: DM, diabetes mellitus; $\mathrm{HbA}_{\mathrm{Ic}}$, glycosilated haemoglobin; LDL, low density cholesterol; HDL, high density cholesterol.

lipids, which reflects the extent of cellular damage. Most popular and frequently used is the determination of MDA by the thiobarbituric acid-reactive substance test and the detection of $\mathrm{F}_{2}$-isoprostanes that reflect oxidative damage to lipids. ${ }^{25,84,86,87}$ Also, concentration measurements of AOX enzymes and other compounds with the same functions (GHS, NADPH, coenzyme Q, and vitamins A, C, and E), are performed in some cases by means of high-performance liquid chromatography. ${ }^{89}$

In Italy, Mancino et al ${ }^{25}$ examined 19 patients with type 2 diabetes mellitus with DR and 14 nondiabetic, age-matched subjects forming a control group. Blood, aqueous humor, and vitreous body samples were collected at the time of surgery (cataract, vitrectomy). MDA concentrations and blood extracorporeal photopheresis were measured with high-performance liquid chromatography. The TAC of the samples was estimated with the oxygen radical absorbancecapacity method. The authors reported that the level of blood and vitreous MDA in the proliferative DR (PDR) subgroup was significantly higher compared to controls and to the noPDR subgroup of patients. The PDR patients also had lower

Table 3 References of glycemic index respect to the glucose (100) in main nutrients.

\begin{tabular}{|c|c|c|c|c|c|c|c|c|c|}
\hline Bread & $\begin{array}{l}\text { Glycemic } \\
\text { index }\end{array}$ & Cereals & $\begin{array}{l}\text { Glycemic } \\
\text { index }\end{array}$ & Fruits & $\begin{array}{l}\text { Glycemic } \\
\text { index }\end{array}$ & Vegetables & $\begin{array}{l}\text { Glycemic } \\
\text { index }\end{array}$ & Dairy & $\begin{array}{l}\text { Glycemic } \\
\text { index }\end{array}$ \\
\hline White bread & 70 & Rice & 55 & Watermelon & 72 & Carrot & 71 & Milk & 34 \\
\hline Rye bread & 50 & Corn & 55 & Mango & 64 & Pumpkin & 75 & Yogurt & 36 \\
\hline Oat bread & 47 & Wheat & 40 & Banana & 53 & Sweet potato & 51 & Ice cream & 36 \\
\hline Macaroni & 45 & Chickpeas & 33 & Kiwi & 52 & Peans & 48 & White sugar & 59 \\
\hline Spaghetti & 35 & Lentils & 29 & Apple & 36 & Potatoes & 70 & Fructose & 20 \\
\hline White beans & 31 & Special K ${ }^{\circledR}$ & 54 & Pear & 33 & Tomatoes & 38 & Honey & 87 \\
\hline Fresh beans & 29 & Cornflakes & 85 & Plum & 24 & Beet & 64 & Soja milk & 18 \\
\hline
\end{tabular}

Note: The glycemic index estimates how much each gram of carbohydrate in a particular food raises the blood glucose level following food consumption (in relation to consumption of pure glucose, which is used as the benchmark, with glucose absorption being $100 \%$ or 100 ). 
levels of TAC at the vitreous body and aqueous humor levels, but not at the blood level, compared to controls and nonproliferative DR (NPDR) patients. In all diabetic patients, the blood extracorporeal photopheresis values were significantly lower, compared to control subjects. These results support the hypothesis that OS and the decreased AOX defenses are associated with the progression of DR to its proliferative form, suggesting that AOX supply may be helpful for correcting OS and for blocking disease progression.

Gene expression can be influenced by the environment, including the exogenous and the endogenous world, which includes such factors as chemicals, light, temperature, metabolism, and hormones that can determine which genes are turned on and off, thereby impacting the way an organism develops and functions. Dolinoy et $\mathrm{al}^{90}$ supplemented the diet of rat mothers with methyl-donating substances, such as folic acid and vitamin $\mathrm{B}_{12}$, and it was found that this type of intervention counteracted the reduction in DNA methylation caused by bisphenol A (a compound that is usually present in plastic drink bottles, including baby bottles). This epigenetic mechanism clearly shows how profoundly environment can affect gene expression in a long-lasting way.

Although diabetes mellitus is a multifactorial disease, ethnicity, sex, genomic factors, age, nutritional characteristics, lifestyle, and even environmental factors can change the genetics. Therefore, measuring solely on glycemic biomarkers may not be sufficient for controlling DR.

\section{Studies on the role of nutritional supplements in eye diseases}

For an optimal nutritional status, as well as for having a healthy body and for being at lesser risk of developing diseases, the dietary guidelines for Americans from the US Department of Health and Human Services ${ }^{91}$ describe a healthy diet as one that: 1) emphasizes fruits, vegetables, whole grains, and fat-free (or low-fat) milk and milk products, 2) includes lean meats, poultry, fish, beans, eggs, and nuts, and 3) is low in saturated fats, trans fats, cholesterol, salt (sodium), and added sugars. However, if additional supplements are needed, these have to be appropriately traded and labeled to display full information about composition, nutritional properties, and safety.

The Mediterranean diet has been strongly associated with a reduction in overall risk for cardiovascular diseases, cancer, and neurodegenerative disorders. ${ }^{92}$ Surprisingly, there are no studies specifically looking at an association between the Mediterranean diet and a presumptive benefit for aging eyes. However, the Mediterranean diet, ${ }^{92-95}$ with variations reflecting influences of the culture and landscape, which has proven to be rich in vitamins, carotenoids, and $\omega-3$ FAs, seems to be a good tool for counteracting oxidative damage linked to age-related eye diseases.

The eyes are at risk of suffering oxidative damage due to a great deal of FAs in the retina, their high exposure to oxygen and light, environmental pollutants, and ultraviolet rays. In addition, the rate of ROS formation in the mitochondria increases through aging. Given this scenario, the most prevalent ocular diseases closely related to OS and the role of diet and nutritional supplements are now revisited.

\section{Dry-eye disorders}

The ocular surface epithelial cell layers (the conjunctiva and cornea) are the most important tissues for protecting the eyes from external injuries. ${ }^{35,37}$ Several studies ${ }^{44-46,50-52,96,97}$ have been published on the role of OS and nutraceutic supplements in DED.

Nutraceutic formulations containing specific AOXs and $\omega-3$ FAs have been assayed in relation to DED, with positive results on subjective symptoms as well as the clinical evolution of the disease, as confirmed by the Ocular Surface Disease Index (OSDI), a personal questionnaire of DED severity, the ophthalmologic examination, expression patterns of immune mediators in tear samples of mild-tomoderate dry eyes with respect to individuals with healthy ocular surface, ${ }^{50}$ and in patients undergoing chronic glaucomatous therapy with antihypertensive eyedrops compared to control eyes. ${ }^{51}$

In another European study, the French ALIENOR (Antioxydants, Lipides Essentiels, Nutrition et Maladies Oculaires) study ${ }^{96}$ analyzed several characteristics of DED, among other eye diseases, such as self-reported dry eye, current use of artificial tears, OSDI score, and the tear breakuptime test. In addition, the authors recorded some nutritional data and performed plasmatic determinations of vitamins and FAs. The results confirmed a slight increase with age of use of artificial tears and OSDI score, as well as the association of eye diseases with history of nutritional status. An update of this study has been recently published..$^{97}$

\section{Glaucoma}

Recent evidence demonstrates the important role of OS in glaucoma pathogenesis. ${ }^{21,23}$ Nutritional supplementation, including Ginkgo biloba, curcumin (derived from a spice), and resveratrol has been recommended for patients with normotensive glaucoma for its beneficial effect on the processes of inflammation and reduction of vascular flow and OS. ${ }^{98,99}$ A correlation was also found between AOX 
supplementation in patients with POAG (in the intermediate stage), a significant percentage of stabilization in the visual field, and in the analysis of optical fibers in relation to the progression of glaucoma.

Coleman et $\mathrm{al}^{100}$ showed that a diet with a low intake of AOXs, particularly retinol and vitamin $B_{1}$, is associated with a high risk of glaucoma. From a total of 1,155 women participating in a study of osteoporotic fractures, Kang et al ${ }^{101}$ diagnosed 95 women with glaucoma. These patients were evaluated (by analysis of optic disk photographs and visual field) for the risk of glaucomatous progression according to the consumption of fruits and vegetables. The study showed less progression of glaucoma in women who frequently consumed carrots, cabbage, green leafy vegetables, and apricots versus those that did not. These results are really interesting, and make us look to the importance of nutrition and OS, as well as the AOX defenses in glaucoma. Moreover, dietary fat consumption in relation to POAG was analyzed in 76,199 women from the Nurses' Health Study and 40,306 men from the Health Professionals Follow-up Study ${ }^{101}$ that were POAG-free. A high ratio of $n-3$ to n-6 PUFAs appears to increase the risk of POAG.

Zanon-Moreno et $\mathrm{al}^{102,103}$ proposed that genetic factors may play a role in modulating the effect of dietary AOX intake on glaucoma. The researchers firstly studied the association between selected polymorphisms in key transporter proteins related to vitamin $\mathrm{C}$ and vitamin $\mathrm{A}$ concentrations and POAG. A total of 300 subjects (150 POAG cases and 150 controls) from a Mediterranean population were recruited to determine the plasmatic concentrations of vitamins $\mathrm{A}$ and $\mathrm{C}$ and the single-nucleotide polymorphisms (SNPs) in genes related to these vitamin concentrations (rs176990 and rs190910 in the RBP1 gene, and rs10063949 and rs1279683 in the $\mathrm{Na}^{+}$-dependent L-ascorbic acid transporters 1 and 2, respectively [encoded by the $S L C 23 A 1$ and $S L C 23 A 2$ genes]). A significant association between the $\operatorname{rs} 1279386(A>G)$ SNP in SLC23A2 and POAG risk was detected. It was also found that POAG patients had lower plasma vitamin A and $\mathrm{C}$ concentrations than the controls (Figure 3A and B). SNPs in $R B P 1$ were not associated with vitamin A concentrations or
POAG risk. A significant association between the rs 1279386 SNP in SLC23A2 and plasma vitamin C concentrations was found in relation to glaucoma risk. The rs10063949 SNP in SLC23A1 was not associated with either plasma vitamin C concentrations or POAG risk. ${ }^{102}$ The same group analyzed the association of selected SNPs in genes related to vitamins $\mathrm{C}$ and E, and GSH-Px activity and POAG risk. In this study, 250 POAG cases and 250 controls were selected, also from the same Mediterranean area. Plasma concentrations of vitamins $\mathrm{C}$ and $\mathrm{E}$ were measured (Figure 3C), and GSH-Px activity was also determined. POAG patients had statistically significant (after correction for multiple testing) lower plasma vitamin $\mathrm{C}(P<0.001)$ and vitamin $\mathrm{E}(P<0.001)$ concentrations than the nonglaucomatous subjects. Higher plasma GSH-Px activity in POAG cases than in controls $(P<0.001)$ was found. Also analyzed were specific SNPs (rs1279683 in the $\mathrm{Na}^{+}$-dependent $\mathrm{L}$-ascorbic acid transporter 2 gene [SLC23A2], rs6994076 in the TTPA gene, rs737723 in the SEC14L2/TAP gene, and rs757228 in the GPX4 gene) in relation to glaucoma risk. A novel association between the rs737723 polymorphism and POAG risk was found that remained statistically significant after adjustment for multiple comparisons. A higher glaucoma risk in GG homozygous individuals was statistically confirmed in association with the rs1279683 polymorphism. Furthermore, a significant $(P<0.05)$ gene-gene interaction between the SEC14L2/TAP and SLC23A2 polymorphisms in determining POAG risk was detected in those subjects who had both risk genotypes at the same time $(P<0.01)$. Any association with POAG risk for the rs6994076 or rs757228 polymorphisms was identified. The rs1279683 and rs6994076 polymorphisms were significantly $(P<0.001)$ associated with plasma vitamins $\mathrm{C}$ and $\mathrm{E}$, respectively. However, the rs757228 polymorphism in the GPX4 gene was not associated with plasma GSH-Px activity. ${ }^{103}$ In these two studies, novel associations between the specific SNPs and higher POAG risk were confirmed. The results also suggested a gene-gene interaction between both polymorphisms that increases POAG risk. These works support the role of vitamin-transporter proteins in the expression
A

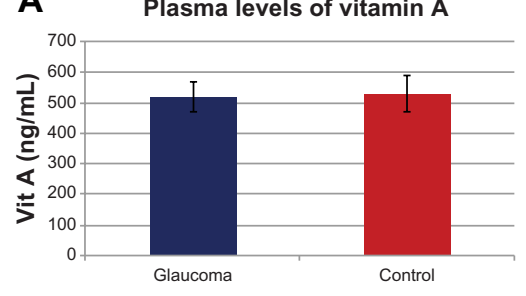

B

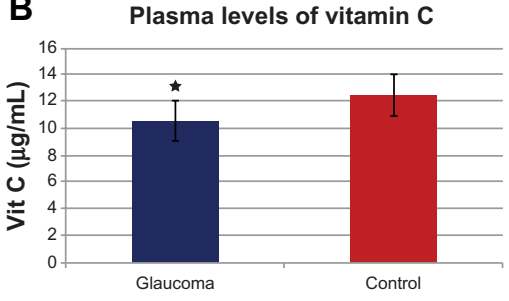

C

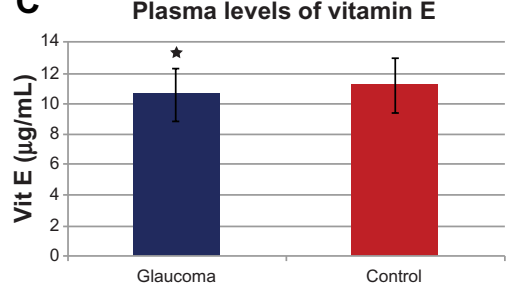

Figure 3 (A-C) Plasma vitamin levels in primary open-angle glaucoma patients. 
and availability of antioxidant vitamins, from both the natural food and nutraceutics supplementation.

\section{Age-related macular degeneration}

AMD is the leading cause of severe vision loss in developed nations. AMD is caused by complex interactions between aging, genetics, ${ }^{27,28,34}$ environmental factors, and comorbid diseases. ${ }^{66,67}$ Numerous studies have analyzed the relationship between the intake of nutritional supplements and AMD, and the most relevant are revisited herein. For a summary on these studies in AMD see Table 4.

The Beaver Dam Eye Study ${ }^{104}$ found an inverse association between vitamin $\mathrm{A}$ and $\mathrm{E}$ intake and the incidence of large drusen, and between zinc intake and the incidence of macropigmentary changes in early AMD. The Rotterdam Eye Study ${ }^{105}$ concluded that a high dietary intake of $\beta$-carotene, vitamins $\mathrm{C}$ and $\mathrm{E}$, and zinc was associated with a substantially reduced risk of AMD in elderly individuals. Clinical trials like the Age-Related Eye Disease Study (AREDS) ${ }^{106}$ randomly assigned patients to daily oral tablets containing AOXs (vitamin C $500 \mathrm{mg}$, vitamin E $400 \mathrm{IU}$, and $\beta$-carotene $15 \mathrm{mg}$ ), zinc $80 \mathrm{mg}$, and copper $2 \mathrm{mg}$, or placebo. This clinical trial showed a statistically significant benefit of the combination of high-dose AOX vitamins and zinc, providing a moderate risk reduction of developing advanced AMD over a median of 6.3 years of follow-up in those at high risk of developing advanced AMD. Increased intake of $\omega-3$ FAs, especially long-chain $\omega-3$ FAs, such as DHA and eicosapentaenoic acid (EPA), has been associated with improving a number of chronic diseases, including AMD. ${ }^{107,108}$ Strong evidence for a beneficial role of $\omega$-3 fatty acids in eye health was found in two cross-sectional studies: the US Twin Study of AgeRelated Macular Degeneration (US Twin) ${ }^{108}$ and AREDS. ${ }^{106}$ Also, lutein and zeaxanthin seems to have a protective effect on the outer retina and RPE by absorbing short-wavelength light and minimizing oxidative damage, thus aiding cellmembrane stability. The Carotenoids in Age-Related Eye Disease Study (CAREDS) ${ }^{109-113}$ concluded that lutein- and zeaxanthin-rich diets may protect against intermediate AMD in female patients aged 75 years or more. The Australian Blue Mountains Eye Study ${ }^{114}$ analyzed the intake of $\omega-3$ fatty acids in diet, as well as higher dietary lutein and zeaxanthin intake. Results displayed a lower incidence of developing forms of initial and advanced AMD. Furthermore, the AREDS reported in 2007 that dietary lutein and zeaxanthin intake was inversely associated with neovascular AMD, geographic atrophy, and large or extensive intermediate drusen. ${ }^{115}$ Thus, the Dietary Ancillary Study of the Eye Disease Case-Control Study (DSEDCS) ${ }^{116}$ revealed a relative risk for AMD estimated according to dietary indicators of AOX status, controlling for smoking and other risk factors, by using multiple logistic regression analyses in which participants with higher

Table 4 Relation of clinical-epidemiological studies on the role of micronutritional supplements in age-related macular degeneration

\begin{tabular}{|c|c|c|}
\hline Cited reference & Study & Findings in AMD \\
\hline 104 & The Beaver Dam Eye Study & $\begin{array}{l}\text { Inverse association between vitamins A, E and zinc intake and incidence of large } \\
\text { drussen and macro-pigmentary changes }\end{array}$ \\
\hline 105 & The Rotterdam Eye Study & $\begin{array}{l}\text { High dietary intake of } \beta \text {-carotene and vitamins } C, E \text { and zinc was associated with } \\
\text { reduced risk of AMD in the elderly }\end{array}$ \\
\hline 106 & $\begin{array}{l}\text { The Age-related Eye Disease Study } \\
\text { (AREDS I) }\end{array}$ & $\begin{array}{l}\text { Daily intake of tablets with vitamins } C, E \text { and } \beta \text {-carotene, zinc and copper } \\
\text { resulted in a moderate reduction of the risk of acquiring advanced AMD }\end{array}$ \\
\hline 113 & $\begin{array}{l}\text { The Carotenoids Age-Related } \\
\text { Eye Disease Study (CAREDS) }\end{array}$ & $\begin{array}{l}\text { Lutein- and zeaxanthin-rich diets may protect against intermediate AMD in } \\
\text { female patients aged }<75 \text { years }\end{array}$ \\
\hline 114 & $\begin{array}{l}\text { The Australian Blue } \\
\text { Mountains Eye Study }\end{array}$ & $\begin{array}{l}\text { Intake of } \omega-3 \text { fatty acids in the diet, as well as higher dietary lutein and } \\
\text { zeaxanthin intake induced a lower incidence of developing AMD initial forms } \\
\text { and AMD advanced forms }\end{array}$ \\
\hline 118 & $\begin{array}{l}\text { The Dietary Ancillary Study of the Eye } \\
\text { Disease Case-Control Study (DSEDCS) }\end{array}$ & $\begin{array}{l}\text { Participants with higher food intake with lutein and zeaxanthin showed a lower } \\
\text { risk of AMD }\end{array}$ \\
\hline 117 & The French POLA Study & $\begin{array}{l}\text { Analysed the levels of antioxidant nutrients in relation to AMD. A lower rate } \\
\text { of progression from moderate AMD to advanced AMD in one eye was found. } \\
\text { Authors concluded that, vitamin E may provide protection against AMD }\end{array}$ \\
\hline 118,122 & $\begin{array}{l}\text { The North American National Health and } \\
\text { Nutrition Examination Survey (NHANES) }\end{array}$ & $\begin{array}{l}\text { Main goal was to analyze the blood levels of vitamin E and AMD and the results } \\
\text { showed a lesser risk of AMD initial stages with elevated levels of this vitamin }\end{array}$ \\
\hline 119 & $\begin{array}{l}\text { The Lutein and Antioxidant Supplementation } \\
\text { study Trial (The veterans LAST) }\end{array}$ & $\begin{array}{l}\text { Found a relationship between the intake of carotenoids and subjective signs of } \\
\text { improvement of vision in } 90 \text { patients with AMD }\end{array}$ \\
\hline 120 & $\begin{array}{l}\text { The Age-Related Eye Diseases Study } \\
\text { (AREDS 2) }\end{array}$ & $\begin{array}{l}\text { Concluded and reported data on the intake of carbohydrates and the risk of } \\
\text { suffering AMD and progression of disease, probably by oxidative damage to protein }\end{array}$ \\
\hline
\end{tabular}

Abbreviations: AMD, age-related macular degeneration; AREDS I, Age-Related Eye Disease Study I; AREDS 2, Age-Related Eye Disease Study 2; CAREDS, The Carotenoids Age-Related Eye Disease Study; DSEDCS, The Dietary Ancillary Study of the Eye Disease Case-Control Study; LAST, the Lutein and Antioxidant Supplementation study Trial (The veterans LAST); NHANES, the North American National Health and Nutrition Examination Survey; POLA, the Pathologies Oculaires Liées à l'Age study. 
food intake with lutein and zeaxanthin showed a lower risk of AMD. In the French POLA Study, ${ }^{117}$ levels of AOX nutrients in relation to AMD were analyzed, and data showed a lower rate of progression from moderate AMD to advanced AMD in one eye. The authors concluded that vitamin E may provide protection against AMD. Current data processing of this study strongly indicates that AMD develops mainly in subjects aged 80 years or older, and in subjects with early age-related maculopathy signs and symptoms. The North American National Health and Nutrition Examination Survey (NHANES) $)^{118}$ was a cross-sectional nested casecontrol study matching subjects on age, sex, and race that was performed using data on adult participants in the third NHANES. Study outcomes included late AMD, defined as neovascular disease or geographic atrophy (5:1 matching), and a composite of both early AMD, defined as soft drusen or pigment irregularities with or without any drusen, and late AMD (1:1 matching). The main goal of this study was to analyze the blood levels of vitamin E and AMD. Data showed a lesser risk of AMD at initial stages with elevated levels of this vitamin. The Lutein and Antioxidant Supplementation Trial (Veterans LAST) ${ }^{119}$ found a relationship between the intake of carotenoids and subjective signs of improvement of vision in 90 patients with AMD. Finally, the most recent results from the AREDS2, ${ }^{120}$ a multicenter, randomized, double-masked, placebo-controlled Phase III study, merit special consideration in this review. It was conducted through 2006-2012 with 4,203 participants aged 50-85 years at risk for progression to advanced AMD. The clinical characteristics of the suitable participants were bilateral large drusen, or large drusen in one eye and advanced AMD in the fellow eye. The main purpose of the AREDS2 was to determine whether adding lutein + zeaxanthin, DHA + EPA, or both to the initial AREDS formulation decreases the risk of developing advanced AMD or not. After a median follow-up of 5 years, 1,940 study eyes (1,608 participants) progressed to advanced AMD. Statistical probabilities of progression to advanced AMD by 5 years of follow-up were $31 \%$ for placebo, $29 \%$ for lutein + zeaxanthin, $31 \%$ for DHA + EPA, and 30\% for lutein + zeaxanthin and DHA + EPA. When compared with placebo in the primary analyses, no statistically significant reduction in the progression to advanced AMD was found. The evaluation of the effects of eliminating $\beta$-carotene from the original AREDS formulation (500 mg vitamin C, $400 \mathrm{IU}$ vitamin $\mathrm{E}$, and $15 \mathrm{mg} \beta$-carotene) and/or lowering the zinc (previously $80 \mathrm{mg}$ zinc as zinc oxide, and $2 \mathrm{mg}$ copper as cupric oxide) is an important point to consider. In fact, zinc decreased copper levels and caused copper-deficiency anemia. $\beta$-carotene elimination from the utilized formulation or the incorporation of a lower dose of zinc had no apparent effect of progression to advanced AMD. Important data reflected that more lung cancers were identified between the $\beta$-carotene versus no- $\beta$-carotene group $(2.0 \%)$ versus 11 (0.9\%) (nominal $P=0.04)$, mostly in former smokers.

The main conclusion of the AREDS $2_{120}$ was that addition of lutein + zeaxanthin, DHA + EPA, or both to the primary formulation did not further reduce risk of progression to advanced AMD. Moreover, AREDS2 ${ }_{120}$ also concluded that lutein + zeaxanthin could appropriately substitute betacarotene in AMD interventional studies with nutraceutics (to avoid the described risk of lung cancer in smokers).

\section{Diabetic retinopathy}

DR is the most common microvascular complication of diabetes mellitus and one of the leading causes of blindness worldwide. Among the studies on the role of AOXs and $\omega-3$ fatty acids in the prevention of DR, the San Luis Valley Diabetes Study ${ }^{121}$ found no protective effect between the AOX nutrients $\beta$-carotene and vitamin $\mathrm{C}$ or $\mathrm{E}$ and $\mathrm{DR}$. The Third National Health and Nutrition Examination ${ }^{124}$ reported that serum levels of $\alpha$-tocopherol and vitamin $C$ were not associated with DR. It was also concluded in the Diabetes Control and Complications Trial ${ }^{123}$ (which included over 1,000 type 1 diabetics) that those patients who followed a low-fat diet decreased the rate of progression of DR a third more than those patients not following the low-fat diet. As for type 2 diabetes, another study found less frequency of DR in subjects who took multivitamins or supplements that included vitamins C and E. ${ }^{124} \omega-3$ PUFAs may also play a beneficial role in DR. In a recent study, the antiangiogenic properties of edible berries were shown. ${ }^{125}$ Brownlee ${ }^{126}$ proposed hyperglycemia as responsible for superoxide anion overproduction (occurring in the mitochondria). This may provide a new concept for future research and drug discovery.

Garcia-Medina et al ${ }^{127}$ designed a follow-up study in the Mediterranean area of Spain with the main goal of evaluating the effect of AOX supplementation on 105 type 2 diabetics with NPDR over a 5-year period, in a similar manner to the follow-up schedule designed by the AREDS. A complete ophthalmic examination and plasmatic determinations of oxidative (MDA) and AOX parameters (total AOX status) were obtained as the baseline. One part of the cohort was randomly assigned to oral AOX supplementation at nutritional doses with the formulation defined in Table 5. The same examinations were performed with 97 diabetic patients who completed the 5-year follow-up period. Best-corrected visual acuity, DR score, MDA, and total AOX status values were compared at the beginning and the end of the follow-up. 
Table 5 Combined formulation of antioxidants utilized in the 5 -year follow-up study on type 2 diabetic patients and diabetic retinopathy

\begin{tabular}{|c|c|c|c|c|c|c|}
\hline Vitalux forte ${ }^{\circledR}$ & ẃ-3 fatty acids & Lutein/zeaxanthin & Vitamin C & Vitamin E & Zinc & Copper \\
\hline Per capsule & $160 \mathrm{mg}$ & 10 mg/l mg & $60 \mathrm{mg}$ & $20 \mathrm{mg}$ & $10 \mathrm{mg}$ & $0.25 \mathrm{mg}$ \\
\hline$\%$ recomended & $100 \%$ & $100 \%$ & $75 \%$ & $167 \%$ & $100 \%$ & $25 \%$ \\
\hline
\end{tabular}

Note: Data from Garcia-Medina J], Pinazo-Duran MD, Garcia-Medina M, Zanon-Moreno V, Pons-Vazquez S. A 5-year follow-up of antioxidant supplementation in type 2 diabetic retinopathy. Eur J Ophthalmol. 201 I;21:637-643. ${ }^{127}$

The authors found that best-corrected visual acuity did not change during the follow-up, irrespective of supplementation. However, the DR stage showed a retardation of progression in the subgroup with supplementation, but worsened in the subgroup with no AOX supplementation. Furthermore, the AOX-supplementation group maintained its AOX plasma status levels, which was related to decreased oxidative plasma activity. The authors concluded that oral AOX supplementation could be a useful adjunctive long-term therapy in the treatment of NPDR. Currently, a new study (the Valencia Diabetic Retinopathy Study [VDRS]) is being carried out to analyze the role of a combined formulation of AOX and $\omega-3$ fatty acids in the risk and progression of DR by evaluating clinical manifestations, biochemical parameters, nutritional facts, and lifestyle, as well as subjective sensations in 350 participants made up of type 1 diabetics, type 2 diabetics, and healthy controls, through a 3-year follow-up. Preliminary data confirmed previous results from our group and others, with a significant increase in plasmatic MDA levels $(P<0.01)$ and decreased total AOX activity $(P<0.001)$ in both diabetic types with respect to the controls.

\section{Adverse effects of vitamins and oligoelements in human health}

It is of maximum interest to ascertain if nutraceutic formulations with vitamins, minerals, and PUFAs may avoid, delay, or modify age-related ocular diseases. All nutraceutic formulations have to be balanced and based on scientific evidence. With the megadoses of vitamins and minerals that have been extensively suggested by different authors, it has to be considered that secondary effects can appear.

Firstly, it has to be said that vitamin E supplementation has been associated with increased risk of heart failure. ${ }^{128}$ In addition, $\beta$-carotene and vitamin $A$ intake have been reported in relation with a significant increased incidence of cancer and mortality rate in smokers and workers exposed to asbestos. ${ }^{129-131}$ Zinc sulfate supplementation was associated with an increased risk of genitourinary disorders during the AREDS. ${ }^{96,120}$ Zinc decreased copper levels and copper deficiency induced anemia. For this reason, copper should be taken with high-dose zinc.

Liposoluble vitamins, particularly vitamin A and vitamin $\mathrm{K}$ and some of its by-products, can induce toxicity. Excess in vitamin A has been associated with birth defects and increased risk of bleeding. Patients with liver disease and high alcohol intake may be at risk for hepatotoxicity from vitamin A supplementation. ${ }^{132}$ Severe toxicity induced by hypervitaminosis A includes eye and liver damage, irritability, headache, visual disturbances, skin redness and peeling, hypercalcemia, delirium, and coma.

Vitamin C mediates the absorption of iron, a prooxidant that can be stored by the organism, and that has been associated with a major risk of cardiovascular diseases and formation of hydroxyl radicals through the reactions of Haber-Weiss and Fenton. ${ }^{3,4}$ Previous reports confirm that a high intake of vitamin $\mathrm{C}$ and vitamin $\mathrm{E}$ slowed the process of cellular aging and increased life expectancy. However, new findings in experimental animals suggest that high-dose supplementation may actually reduce lifespan by $11 \%$ and $26 \%$ for vitamins $\mathrm{E}$ and $\mathrm{C}$ respectively for voles in the cold, and by $17 \%$ and $18 \%$ for vitamins $\mathrm{E}$ and $\mathrm{C}$ respectively for voles in the warm. This study also confirms that major differences exist in the effects of high-dose AOXs on oxidative damage and life span across species. $^{133}$

Appropriate vitamin E dosing can be confusing. Current guidelines provide recommended dietary allowances and upper tolerable threshold for vitamin $\mathrm{E}$ in milligrams. It is usually recognized that most commercial products remain labeled in international units. ${ }^{134}$ It was suggested that vitamin E supplementation may potentiate the effects of warfarin (Coumadin); therefore, taking vitamin E along with the latter can increase the risk of bruising and bleeding.

In spite of these reports, it is important to say that the Food Standards Agency ${ }^{135}$ showed that there were only eleven reported reactions from nutritional supplements over an 11 year follow-up period. The majority was in the lowest category of harm. When compared with other foods or medicines, food supplements in general displayed better results. 


\section{Final comments}

Micronutrient supplementation remains a subject of debate worldwide. Still, many ophthalmologists remain skeptical about nutraceutic supplements and their role at the initiation or progression of age-related eye diseases. However, it is becoming scientifically more evident that optimal nutrition status helps in preventing OS and subsequent OS-related ocular disorders.

The main epidemiological studies have focused basically on formulations including vitamins $\mathrm{C}$ and $\mathrm{E}$, carotenoids, flavonoids, selenium, and zinc. Perhaps we have to include other micronutrients that could influence certain processes related to eye health. More data from studies in different populations may improve our knowledge about the specific changes in diet and lifestyle that could positively influence the development of ocular conditions that are becoming more common as the population ages. A greater number of epidemiological studies on diet and the use of nutraceutics in Spain and other European countries, as well as the repercussion for on ocular diseases, have to be done to maximize eye health in the elderly.

Today, there is general agreement that ROS are involved in the physical, biochemical, molecular, and pathological changes associated with aging. Oxidative damage to lipids, proteins, and nucleic acids accumulates and increases with age, whereas AOX defenses decrease in parallel. These facts are closely related to such age-related diseases as DED, POAG, AMD, and DR. As one of the modifiable lifestyle factors is nutrition, elderly people should be informed about the importance of a healthy diet and the exact role of micronutritional supplement intake, since it has a positive effect on the body and may help to decrease the risk of ocular diseases and visual impairment associated with aging.

\section{Disclosure}

Roberto Gallego-Pinazo is a consultant for Novartis, Alcon, and Zeiss. Maria I Lopez-Galvez is a consultant for Allergan, Alimera, Novartis. The other authors report no conflicts of interest in this work.

\section{References}

1. Krebs HA. Some aspects of the regulation of fuel supply in omnivorous animals. Adv Enzyme Regul. 1972;10:397-420.

2. Cheeseman KH, Slater TF. An introduction to free radical biochemistry. Br Med Bull. 1993;49:481-493.

3. Haber F, Weiss J. Über die Katalyse des Hydroperoxydes [On the catalysis of hydroperoxides]. Naturwissenschaften. 1932;20:948-950.

4. Fenton HJ. The oxidation of tartaric acid in presence of iron. J Chem Soc Trans. 1894;65:899-910.
5. Goldstein S, Meyerstein D, Czapski G. The Fenton reagents. Free Radic Biol Med. 1993;15:435-445.

6. Ames BN, Shigenaga MK. Oxidants are a major contributor to aging. Ann N Y Acad Sci. 1992;663:85-96.

7. Sies H. Oxidative stress: introductory remarks. In: Sies H, editor. Oxidative Stress. London: Academic Press; 1985:1-7.

8. D'Autréaux B, Toledano MB. ROS as signalling molecules: mechanisms that generate specificity in ROS homeostasis. Nat Rev Mol Cell Biol. 2007;8:813-824.

9. Halliwell B. Free radicals and antioxidants: updating a personal view. Nutr Rev. 2012;70:257-265.

10. McCord JM, Fridovich I. Superoxide dismutase. An enzymic function for erythrocuprein (hemocuprein). J Biol Chem. 1969;244:6049-6055.

11. Harman D. Ageing: a theory based on free radical and radiation chemistry. J Gerontol. 1956;2:298-300.

12. Gerschman R, Fenn W. Ascorbic acid content of adrenal glands of rat in oxygen poisoning. Am J Physiol. 1952;176:6-8.

13. Gerschman R, Nadig PW, Snell AC, Nye SW. Effect of high oxygen concentrations on eyes of newborn mice. Am J Physiol. 1954;179: 639-639.

14. Gerschman R, Gilbert DL, Nye SW, Fenn W. Influence of x-irradiation on oxygen poisoning in mice. Proc Soc Exp Biol Med. 1954;86: 27-29.

15. Agil A, Durán R, Barrero F, et al. Plasma lipid peroxidation in sporadic Parkinson's. Role of the L-dopa. J Neurol Sci. 2006;240:31-36.

16. Choi J, Sullards MC, Olzmann JA, et al. Oxidative damage of DJ-1 is linked to sporadic Parkinson and Alzheimer diseases. J Biol Chem. 2006;281:10816-10824.

17. Alaluf S, Muir-Howie H, Hu HL, Evans A, Green MR. Atmospheric oxygen accelerates the induction of a post-mitotic phenotype in human dermal fibroblasts: the key protective role of glutathione. Differentiation. 2000;66:147-155.

18. Alexandrova M, Bochev P, Markova V, et al. Dynamics of free radical processes in acute ischemic stroke: influence on neurological status and outcome. J Clin Neurosci. 2004;11:501-506.

19. Ames BN, Shigenaga MK, Hagen TM. Oxidants, antioxidants and degenerative diseases of aging. Proc Natl Acad Sci U S A. 1993;90: 7915-7922.

20. Conner EM, Grisham MB. Inflammation, free radicals, and antioxidants. Nutrition. 1996;12:274-277.

21. Williams DL. Oxidative stress and the eye. Vet Clin North Am Small Anim Pract. 2008;38:179-192.

22. Spector A. Oxidative stress-induced cataract: mechanism of action. FASEB J. 1995;9:1173-1182.

23. Zanon-Moreno V, Marco-Ventura P, Lleo-Perez A, et al. Oxidative stress in primary open angle glaucoma. J Glaucoma. 2008;17:263-268.

24. Pinazo-Durán MD, Azorin I, Montoliu C, Guerri C, Renau-Piqueras J. Free radicals are involved in the alcoholic optic neuropathy. Alcohol Clin Exp Res. 1998;22:A84.

25. Mancino R, Di Pierro D, Varesi C, et al. Lipid peroxidation and total antioxidant capacity in vitreous, aqueous humor, and blood samples from patients with diabetic retinopathy. Mol Vis. 2011;17:1298-1304.

26. Melo P, Zanon-Moreno V, Alves CJ, et al. Oxidative stress response in the adult rat retina and plasma after repeated administration of methamphetamine. Neurochem Int. 2010;56:431-436.

27. Beatty S, Koh H, Phil M, Henson D, Boulton M. The role of oxidative stress in the pathogenesis of age-related macular degeneration. Surv Ophthalmol. 2000;45:115-134.

28. Margrain TH, Boulton M, Marshall J, Sliney DH. Do blue light filters confer protection against age-related macular degeneration? Prog Retin Eye Res. 2004;23:523-531.

29. Rahman K. Studies on free radicals, antioxidants and co-factors. Clin Interv Aging. 2007;2:219-236.

30. Carocho M, Ferreira IC. A review on antioxidants, prooxidants and related controversy: natural and synthetic compounds, screening and analysis methodologies and future perspectives. Food Chem Toxicol. 2013;51:15-25. 
31. Birben E, Sahiner UM, Sackesen C, Erzurum S, Kalayci O. Oxidative stress and antioxidant defense. World Allergy Organ J. 2012;5: 9-19.

32. Doly M, Droy-Lefaix MT, Braquet P. Oxidative stress in diabetic retina. EXS. 1992;62:299-307.

33. Yadav UC, Kalariya NM, Ramana KV. Emerging role of antioxidants in the protection of uveitis complications. Curr Med Chem. 2011;18: 931-942.

34. Prashar S, Pandav SS, Gupta A, Nath R. Antioxidant enzymes in RBCs as a biological index of age related macular degeneration. Acta Ophthalmol (Copenh). 1993;71:214-218.

35. Perry HD. Dry eye disease: pathophysiology, classification, and diagnosis. Am J Manag Care. 2008;14:S79-S87.

36. Tavares FP, Fernandes RS, Bernardes TF, Bonfioli AA, Soares EJ. Dry eye disease. Semin Ophthalmol. 2010;25:84-93.

37. Labbé A, Brignole-Baudouin F, Baudouin C. [Ocular surface investigations in dry eye]. J Fr Ophtalmol. 2007;30:76-97. French.

38. Schein OD, Muñoz B, Tielsch JM, Bandeen-Roche K, West S. Prevalence of dry eye among the elderly. Am J Ophthalmol. 1997;124: 723-728.

39. Muñoz B, West SK, Rubin GS, et al. Causes of blindness and visual impairment in a population of older Americans: the Salisbury Eye Evaluation Study. Arch Ophthalmol. 2000;118:819-825.

40. Moss SE, Klein R, Klein BE. Long-term incidence of dry eye in an older population. Optom Vis Sci. 2008;85:668-674.

41. Schaumberg DA, Sullivan DA, Buring JE, Dana MR. Prevalence of dry eye syndrome among US women. Am J Ophthalmol. 2003;136: 318-326.

42. Gipson IK, Spurr-Michaud S, Argüeso P, Tisdale A, Ng TF, Russo CL. Mucin gene expression in immortalized human corneal-limbal and conjunctival epithelial cell lines. Invest Ophthalmol Vis Sci. 2003;44: 2496-2506.

43. Zuclich JA, Connolly JS. Ocular damage induced by near-ultraviolet laser radiation. Invest Ophthalmol Vis Sci. 1976;15:760-764.

44. Higuchi A, Takahashi K, Hirashima M, Kawakita T, Tsubota K. Selenoprotein P controls oxidative stress in cornea. PLoS One. 2010;5:e9911.

45. Uchino Y, Kawakita T, Ishii T, Ishii N, Tsubota K. A new mouse model of dry eye disease: oxidative stress affects functional decline in the lacrimal gland. Cornea. 2012;31 Suppl 1:S63-S67.

46. Nakamura S, Shibuya M, Nakashima H, et al. Involvement of oxidative stress on corneal epithelial alterations in a blink-suppressed dry eye. Invest Ophthalmol Vis Sci. 2007;48:1552-1558.

47. VanDerMeid KR, Su SP, Krenzer KL, Ward KW, Zhang JZ. A method to extract cytokines and matrix metalloproteinases from Schirmer strips and analyze using Luminex. Mol Vis. 2011;17:1056-1063.

48. Enríquez-de-Salamanca A, Castellanos E, Stern ME, et al. Tear cytokine and chemokine analysis and clinical correlations in evaporative-type dry eye disease. Mol Vis. 2010;16:862-873.

49. Baudouin C, Brignole F, Becquet F, Pisella PJ, Goguel A. Flow cytometry in impression cytology specimens. A new method for evaluation of conjunctival inflammation. Invest Ophthalmol Vis Sci. 1997;38: $1458-1464$

50. Pinazo-Durán MD, Galbis-Estrada C, Pons-Vázquez S, Cantú-Dibildox J, Marco-Ramírez C, Benítez-del-Castillo J. Effects of a nutraceutical formulation based on the combination of antioxidants and $\omega-3$ essential fatty acids in the expression of inflammation and immune response mediators in tears from patients with dry eye disorders. Clin Interv Aging. 2013;8:139-148.

51. Galbis-Estrada C, Pinazo-Durán MD, Cantú-Dibildox J, MarcoRamírez C, Diaz-Llopis M, Benítez-del-Castillo J. Patients undergoing antihypertensive treatment with antihypertensive eye drops responded positively with respect to their ocular surface disorder to oral supplementation with antioxidants and essential fatty acids. Clin Interv Aging. 2013;8:711-719.

52. Tsubota K, Kawashima M, Inaba T, et al. The antiaging approach for the treatment of dry eye. Cornea. 2012;31 Suppl 1:S3-S8.

53. Weinreb RN, Khaw PT. Primary open-angle glaucoma. Lancet. 2004;363:1711-1720.
54. Osborne NN, Wood JP, Chidlow G, Bae JH, Melena J, Nash MS. Ganglion cell death in glaucoma: what do we really know? $\mathrm{Br} J$ Ophthalmol. 1999;83:980-986.

55. Huang W, Dobberfuhl A, Filippopoulos T, et al. Transcriptional up-regulation and activation of initiating caspases in experimental glaucoma. Am J Pathol. 2005;167:673-681.

56. Pinazo-Durán MD, Gallego-Pinazo R, Zanón-Moreno V, Serrano M. Glaucoma genetics - regulation of cell surviving and death in the retina. In: Rumelkt S, editor. Glaucoma: Basic and Clinical Concepts. Rijeka, Croatia: InTech; 2011:207-224.

57. Saccà SC, Izzotti A. Oxidative stress and glaucoma: injury in the anterior segment of the eye. Prog Brain Res. 2008;173:385-407.

58. Tezel G. Oxidative stress in glaucomatous neurodegeneration: mechanisms and consequences. Prog Retin Eye Res. 2006;25:490-513.

59. Pinazo-Durán MD, Zanón-Moreno V, García-Medina JJ, Gallego-Pinazo R. Evaluation of presumptive biomarkers of oxidative stress, immune response and apoptosis in primary open-angle glaucoma. Curr Opin Ophthalmol. 2013;13:98-107.

60. Bazan NG. Survival signaling in retinal pigment epithelial cells in response to oxidative stress: significance in retinal degenerations. $A d v$ Exp Med Biol. 2006;572:531-540.

61. Kennedy CJ, Rakoczy PE, Constable IJ. Lipofuscin of the retinal pigment epithelium: a review. Eye (Lond). 1995;9:763-771.

62. Cai J, Nelson KC, Wu M, Sternberg P Jr, Jones DP. Oxidative damage and protection of the RPE. Prog Retin Eye Res. 2000;19:205-221.

63. Mukherjee PK, Marcheselli VL, Serhan CN, Bazan NG. Neuroprotectin D1: a docosahexaenoic acid-derived docosatriene protects human retinal pigment epithelial cells from oxidative stress. Proc Natl Acad Sci U SA. 2004;101:8491-8496.

64. Bazan NG. Neuroprotectin D1 (NPD1): a DHA-derived mediator that protects brain and retina against cell injury-induced oxidative stress. Brain Pathol. 2005;15:159-166.

65. Calandria JM, Mukherjee PK, de Rivero Vaccari JC, Zhu M, Petasis NA, Bazan NG. Ataxin-1 poly(Q)-induced proteotoxic stress and apoptosis are attenuated in neural cells by docosahexaenoic acid-derived neuroprotectin D1. J Biol Chem. 2012;287:23726-23739.

66. Klein R, Peto T, Bird A, Vannewkirk MR. The epidemiology of age related macular degeneration. Am J Ophthalmol. 2004;137: 486-495.

67. Curcio CA, Johnson M, Rudolf M, Huang JD. The oil spill in ageing Bruch membrane. Br J Ophthalmol. 2011;95:1638-1645.

68. Faghir Z, Bazan NG. PI3K/Akt and mTOR/p70S6K pathways mediate neuroprotectin D1-induced retinal pigment epithelial cell survival during oxidative stress-induced apoptosis. Exp Eye Res. 2010;90:718-725.

69. Klettner A. Oxidative stress induced cellular signaling in RPE cells. Front Biosci (Schol Ed). 2012;4:392-411.

70. Koenekoop R. The gene for Stargardt disease, ABCA4, is a major retinal gene: a mini-review. Ophthalmic Genet. 2003;24:75-80.

71. Nowak JZ. Oxidative stress, polyunsaturated fatty acids-derived oxidation products and bisretinoids as potential inducers of CNS diseases: focus on age-related macular degeneration. Pharmacol Rep. 2013;65:288-304

72. Castilho A, Aveleira CA, Leal EC, et al. Heme oxygenase-1 protects retinal endothelial cells against high glucose- and oxidative/nitrosative stress-induced toxicity. PLoS One. 2012;7:e42428.

73. Sparrow JR, Zhou J, Ben-Shabat S, Vollmer H, Itagaki Y, Nakanishi K. Involvement of oxidative mechanisms in blue-light-induced damage to A2E-laden RPE. Invest Ophthalmol Vis Sci. 2002;43(4):1222-1227.

74. Maleki S, Gopalakrishnan S, Ghanian Z, et al. Optical imaging of mitochondrial redox state in rodent model of retinitis pigmentosa. J Biomed Opt. 2013;18:16004.

75. Zhuo Y, Luo H, Zhang K. Leber hereditary optic neuropathy and oxidative stress. Proc Natl Acad Sci U S A. 2012;109:19882-19883.

76. Pinazo-Durán MD, Verdejo C, Azorín I, Renau-Piqueras J, Iborra FJ. Colocalization of aldehyde dehydrogenases and Fe/NADPH-induced lipid peroxidation in tissue sections of rat retina. Ophthalmic Res. 2000;32:61-68. 
77. Galbis-Estrada C, Pons-Vázquez S, Gallego-Pinazo R, et al. Glutathione-dependent formaldehyde dehydrogenase (ADH3) and low $\mathrm{km}$ mitochondrial aldehyde dehydrogenase (ALDH2). New evidence for differential expression in the rat retina in response to oxidative stress. Free Radic Res. 2012;46:77-84.

78. Rogers BS, Symons RC, Komeima K, et al. Differential sensitivity of cones to iron-mediated oxidative damage. Invest Ophthalmol Vis Sci. 2007; 48:438-445.

79. Dentchev T, Hahn P, Dunaief JL. Strong labeling for iron and the ironhandling proteins ferritin and ferroportin in the photoreceptor layer in age-related macular degeneration. Arch Ophthalmol. 2005;123: 1745-1746.

80. He X, Hahn P, Iacovelli J, et al. Iron homeostasis and toxicity in retinal degeneration. Prog Retin Eye Res. 2007;26:649-673.

81. Song D, Song Y, Hadziahmetovic M, Zhong Y, Dunaief JL. Systemic administration of the iron chelator deferiprone protects against lightinduced photoreceptor degeneration in the mouse retina. Free Radic Biol Med. 2012;53:64-71.

82. Arden GB, Sivaprasad S. Hypoxia and oxidative stress in the causation of diabetic retinopathy. Curr Diabetes Rev. 2011;7:291-304.

83. Son SM. Role of vascular reactive oxygen species in development of vascular abnormalities in diabetes. Diabetes Res Clin Pract. 2006; 77 Suppl 1:S65-S70.

84. Gupta MM, Chari S. Lipid peroxidation and antioxidant status in patients with diabetic retinopathy. Indian J Physiol Pharmacol. 2005;49: 187-192.

85. Verdejo C, Marco P, Renau-Piqueras J, Pinazo-Duran MD. Lipid peroxidation in proliferative vitreoretinopathies. Eye (Lond). 1999;13: 183-188.

86. Robison WG Jr, Jacot JL, Katz ML, Glover JP. Retinal vascular changes induced by the oxidative stress of alpha-tocopherol deficiency contrasted with diabetic microangiopathy. J Ocul Pharmacol Ther. 2000;16:109-120.

87. Martín-Gallán P, Carrascosa A, Gussinyé M, Domínguez C. Biomarkers of diabetes-associated oxidative stress and antioxidant status in young diabetic patients with or without subclinical complications. Free Radic Biol Med. 2003;34:1563-1574.

88. Valko M, Leibfritz D, Moncol J, Cronin MT, Mazuz M, Telsen J. Free radicals and antioxidants in normal physiological functions and human disease. Int J Biochem Cell Biol. 2007;39:44-84.

89. Pácal L, Varvařovská J, Rušavý Z, et al. Parameters of oxidative stress, DNA damage and DNA repair in type 1 and type 2 diabetes mellitus. Arch Physiol Biochem. 2011;117:222-230.

90. Dolinoy DC, Huang D, Jirtle RL. Maternal nutrient supplementation counteracts bisphenol A-induced DNA hypomethylation in early development. Proc Natl Acad Sci U S A. 2007;104:13056-13061.

91. US Department of Health and Human Services. Dietary guidelines for Americans, 2010. Available from: http://www.dietaryguidelines.gov. Accessed December 19, 2013.

92. Keys A, Menotti A, Karvonen MJ, et al. The diet and 15-year death rate in the seven countries study. Am J Epidemiol. 1986;124:903-915.

93. Keys A. Mediterranean diet and public health: personal reflections. Am J Clin Nutr. 1995;61:1321S-1323S.

94. Sofi F, Cesari F, Abbate R, Gensini GF, Casini A. Adherence to Mediterranean diet and health status: meta-analysis. BMJ. 2008;377: a1344.

95. Serra-Majem L, Roman B, Estruch R. Scientific evidence of interventions using the Mediterranean diet: a systematic review. Nutr Rev. 2006;64:S27-S47.

96. Delcourt C, Korobelik JF, Barberger-Gateau P, et al. Nutrition and age-related eye diseases: the ALIENOR (Antioxydants, LIpides Essentiels, Nutrition et Maladies OculaiRes) study. J Nutr Health Aging. 2009; 14:854-861

97. Malet F, Le Goff M, Colin J, et al. Dry eye disease in French elderly subjects: the Alienor Study. Acta Ophthalmol. Epub June 7, 2013.

98. Quaranta L, Bettelli S, Uva MG, Semeraro F, Turano R, Gandolfo E. Effect of Ginkgo biloba extract on preexisting visual field damage in normal tension glaucoma. Ophthalmology. 2003;110:2:359-362.
99. Ritch R. Potential role for Ginko biloba extract in the treatment of glaucoma. Med Hypotheses. 2000;54:221-235.

100. Coleman AL, Stone KL, Kodjebacheva G, et al. Glaucoma risk and the consumption of fruits and vegetables among older women in the study of osteoporotic fractures. Am J Ophthalmol. 2008;145:1081-1089.

101. Kang JH, Pasquale LR, Willett WC, et al. Dietary fat consumption and primary open-angle glaucoma. Am Soc Clin Nutr. 2004;79: 5755-5764.

102. Zanon-Moreno V, Asensio-Marquez EM, Ciancotti-Oliver L, et al. Effects of polymorphisms in vitamin E-, vitamin C-, and glutathione peroxidase-related genes on serum biomarkers and associations with glaucoma. Mol Vis. 2013;19:231-242.

103. Zanon-Moreno V, Ciancotti-Olivares L, Asencio J, et al. Association between a SLC23A2 gene variation, plasma vitamin C levels, and risk of glaucoma in a Mediterranean population. Mol Vis. 2011;17: 2997-3004.

104. VandenLangenberg GM, Mares-Perlman JA, Klein R, Klein BE, Brady WE, Palta M. Associations between antioxidant and zinc intake and the 5-year incidence of early age-related maculopathy in the Beaver Dam Eye Study. Am J Epidemiol. 1998;148:204-214.

105. Van Leeuwen R, Boekhoorn S, Vingerling JR, et al. Dietary intake of antioxidants and risk of age-related macular degeneration. JAMA. 2005;294:3101-3107.

106. Age-Related Eye Disease Study Research Group. A randomized, placebo-controlled, clinical trial of high-dose supplementation with vitamins $\mathrm{C}$ and $\mathrm{E}$, beta carotene, and zinc for age-related macular degeneration and vision loss: AREDS report no 8. Arch Ophthalmol. 2001;119:1417-1436.

107. Connor KM, SanGiovanni JP, Lofqvist C, et al. Increased dietary intake of omega-3-polyunsaturated fatty acids reduces pathological retinal angiogenesis. Nat Med. 2007;13:868-873.

108. Seddon JM, George S, Rosner B. Cigarette smoking, fish consumption, omega-3 fatty acid intake, and associations with age-related macular degeneration: the US Twin Study of Age-Related Macular Degeneration. Arch Ophthalmol. 2006;124:995-1001.

109. SanGiovanni JP, Chew EY, Agrón E, et al. The relationship of dietary omega-3 long-chain polyunsaturated fatty acid intake with incident age-related macular degeneration. AREDS report no. 23. Arch Ophthalmol. 2008;126:1274-1279.

110. Krinsky NI, Landrum JT, Bone RA. Biologic mechanisms of the protective role of lutein and zeaxanthin in the eye. Annu Rev Nutr. 2003;23:171-201.

111. Semba RD, Dagnelie G. Are lutein and zeaxanthin conditionally essential nutrients for eye health? Med Hypotheses. 2003;61:465-472.

112. Schweigert FJ, Reimann J. [Micronutrients and their relevance for the eye - function of lutein, zeaxanthin and omega-3 fatty acids]. Klin Monbl Augenheilkd. 2011;228:537-543. German.

113. Moeller SM, Parekh N, Tinker L, et al. Associations between intermediate age-related macular degeneration and lutein and zeaxanthin in the Carotenoids in Age-Related Eye Disease study (CAREDS): ancillary study of the Women's Health Initiative. Arch Ophthalmol. 2006;124:1151-1162.

114. Tan JS, Wang JJ, Flood V, Rochtchina E, Smith W, Mitchell P. Dietary antioxidants and the long-term incidence of age-related macular degeneration: the Blue Mountains Eye Study. Ophthalmology. 2008;115:334-341.

115. Age-Related Eye Disease Study Research Group, SanGiovanni JP, Chew EY, et al. The relationship of dietary carotenoid and vitamin A, $\mathrm{E}$, and $\mathrm{C}$ intake with age-related macular degeneration in a case control study: AREDS report no 22. Arch Ophthalmol. 2007;125: 1225-1232.

116. Seddon JM, Ajani UA, Sperduto RD, et al. Dietary carotenoids, vitamins A, $\mathrm{C}$, and $\mathrm{E}$, and advanced age-related macular degeneration. Eye Disease Case-Control Study Group. JAMA. 1994;272:1413-1420.

117. Delcourt C, Cristol JP, Tessier F, Léger CL, Descomps B, Papoz L. Age-related macular degeneration and antioxidant status in the POLA study. POLA Study Group. Pathologies Oculaires Liées à l'Age. Arch Ophthalmol. 1999;117:1384-1390. 
118. Mares-Perlman JA, Fisher AI, Klein R, et al. Lutein and zeaxanthin in the diet and serum and their relation to age-related maculopathy in the third national health and nutrition examination survey. $\mathrm{Am} \mathrm{J}$ Epidemiol. 2001;153:424-432.

119. Richer S, Stiles W, Statkute L. Double-masked, placebo-controlled, randomized trial of lutein and antioxidant supplementation in the intervention of atrophic age-related macular degeneration: the Veterans LAST study (Lutein Antioxidant Supplementation Trial). Optometry. 2004;75:216-230.

120. Age-Related Eye Disease Study 2 Research Group. Lutein + zeaxanthin and omega-3 fatty acids for age-related macular degeneration: the Age-Related Eye Disease Study 2 (AREDS2) randomized clinical trial. JAMA. 2013;309:2005-2015.

121. Mayer-Davis EJ, Bell RA, Reboussin BA, Rushing J, Marshall JA, Hamman RF. Antioxidant nutrient intake and diabetic retinopathy: the San Luis Valley Diabetes Study. Ophthalmology. 1998;105: 2264-2270.

122. Weiner DE, Tighiouart H, Reynolds R, Seddon JM. Kidney function, albuminuria and age-related macular degeneration in NHANES III. Nephrol Dial Transplant. 2011;26:3159-3165.

123. [No authors listed]. Diabetes Control and Complications Trial (DCCT): results of feasibility study. The DCCT Research Group. Diabetes Care. 1987;10:1-19.

124. Millen AE, Gruber M, Klein R, Klein BE, Palta M, Mares JA. Relations of serum ascorbic acid and alpha-tocopherol to diabetic retinopathy in the Third National Health and Nutrition Examination Survey. Am $J$ Epidemiol. 2003;158:225-233.

125. Roy S, Khanna S, Alessio HM, et al. Anti-angiogenic property of edible berries. Free Radic Res. 2002;36:9:1023-1031.

126. Brownlee M. Biochemistry and molecular cell biology of diabetic complications. Nature. 2011;414:813-820.
127. Garcia-Medina JJ, Pinazo-Duran MD, Garcia-Medina M, Zanon-Moreno V, Pons-Vazquez S. A 5-year follow-up of antioxidant supplementation in type 2 diabetic retinopathy. Eur J Ophthalmol. 2011;21:637-643.

128. Lonn E, Bosch J, Yusuf S, et al. Effects of long-term vitamin E supplementation on cardiovascular events and cancer: a randomized controlled trial. JAMA. 2005;293:1338-1347.

129. Rodríguez-Castilla V, Cuadrado C, Pozo S, Moreiras O. Concentraciones plasmáticas de carotenos y vitaminas antioxidantes en personas de edad avanzada: influencia del tabaquismo. Proyecto HALE [Plasmatic concentrations of carotenoids and antioxidant vitamins in elder people: influence of smoking. Hale Project]. Clin Investig Arterioscler. 2005;17:101-111.

130. [No authors listed]. The effect of vitamin $\mathrm{E}$ and beta carotene on the incidence of lung cancer and other cancers in male smokers. The Alpha Tocopherol, Beta Carotene Cancer Prevention Study Group. N Engl J Med. 1994;330:1029-1035.

131. Omenn GS, Goodman GE, Thornquist MD, et al. Effects of a combination of beta carotene and vitamin A on lung cancer and cardiovascular disease. N Engl J Med. 1996;334:1150-1155.

132. Fosmire GJ. Zinc toxicity. Am J Clin Nutr. 1990;51:225-227.

133. Block KI, Koch AC, Mead MN, Tothy PK, Newman RA, Gyllenhaal C. Impact of antioxidant supplementation on chemotherapeutic toxicity: a systematic review of the evidence from randomized controlled trials. Int J Cancer. 2008;15;123:1227-1239.

134. Selman C, McLaren JS, Collins AR, Duthie GG, Speakman JR. Deleterious consequences of antioxidant supplementation on lifespan in a wild-derived mammal. Biol Lett. 2013;9:1-5.

135. Food and Nutrition Board, Institute of Medicine. Copper. Dietary reference intakes for vitamin $\mathrm{A}$, vitamin $\mathrm{K}$, boron, chromium, copper, iodine, iron, manganese, molybdenum, nickel, silicon, vanadium, and zinc. Washington, D.C.: National Academy Press; 2001:224-257.
Clinical Interventions in Aging

\section{Publish your work in this journal}

Clinical Interventions in Aging is an international, peer-reviewed journal focusing on evidence-based reports on the value or lack thereof of treatments intended to prevent or delay the onset of maladaptive correlates of aging in human beings. This journal is indexed on PubMed Central, MedLine, the American Chemical Society's 'Chemical Abstracts Ser-

\section{Dovepress}

vice' (CAS), Scopus and the Elsevier Bibliographic databases. The manuscript management system is completely online and includes a very quick and fair peer-review system, which is all easy to use. Visit $\mathrm{http}: / /$ www.dovepress.com/testimonials.php to read real quotes from published authors. 